\title{
Microhabitat type determines the composition of nematode communities associated with sediment-clogged cold-water coral framework in the Porcupine Seabight (NE Atlantic)
}

\author{
M. Raes*, A. Vanreusel \\ Marine Biology Section, Biology Department, Ghent University, Sterre complex-Building S8, Krijgslaan 281, B-9000 Gent, Belgium
}

Received 2 November 2005; received in revised form 25 August 2006; accepted 30 August 2006

\begin{abstract}
The nematofauna associated with a cold-water coral degradation zone in the Porcupine Seabight (NE Atlantic) was investigated. This is the first comprehensive study of nematodes associated with cold-water corals. This research mainly aimed to investigate the influence of microhabitat type on nematode community structure. Three distinct microhabitats for nematodes were distinguished: dead coral fragments, glass sponge skeletons and the underlying sediment. The nematode assemblages associated with these three microhabitats were significantly different from each other. Coral and sponge substrata lie relatively unprotected on the seafloor and are consequently more subjected to strong currents than the underlying sediment. As a result, both large biogenic substrata were characterized by higher abundances of taxa that are less vulnerable and more adapted to physical disturbance, whereas the underlying sediment yielded more slender, sedimentdwelling taxa. Typically epifaunal taxa, such as Epsilonematidae and Draconematidae, were especially abundant on dead coral fragments, where they are thought to feed on the microbial biofilm which covers the coral surface. Several epifaunal genera showed significant preferences for this microhabitat, and Epsilonema (Epsilonematidae) was dominant here. Sponge skeletons are thought to act as efficient sediment traps, resulting in a lower abundance of epifaunal taxa compared to coral fragments. The underlying sediment was dominated by taxa typical for slope sediments. The considerable degree of overlap between the communities of each microhabitat is attributed to sediment infill between the coral branches and sponge spicules. It is assumed that the nematofauna associated with large biogenic substrata is composed of a typical sedimentdwelling background community, supplemented with taxa adapted to an epifaunal life strategy. The extent to which these taxa contribute to the community depends on the type of the substratum. Selective deposit feeders were dominant on sponge skeletons and in the underlying sediment, whereas coral fragments were dominated by epistratum feeders. The presence of a microbial biofilm on the coral fragments is proposed as an explanation for the significant preference of epistratum feeders for this microhabitat. Densities in the underlying sediment were low in comparison with other studies, but biodiversity was higher here than on the coral and sponge fragments, a difference which is attributed to lower disturbance. Nevertheless, the large biogenic substrata provide a microhabitat for rare, epifaunal taxa, and fragments of both substrata within the sediment increase habitat complexity and hence biodiversity.
\end{abstract}

(C) 2006 Elsevier Ltd. All rights reserved.

Keywords: Cold-water corals; Meiobenthos; Nematodes; Community composition; Microhabitats; Biodiversity; North-East Atlantic; Porcupine Seabight

${ }^{*}$ Corresponding author. Tel.: + $32(0) 92648531$; fax: + $32(0) 92648598$.

E-mail address: maarten.raes@ugent.be (M. Raes). 


\section{Introduction}

Until recently, most studies on deep-sea meiofauna focused on the interstitial and mud-dwelling meio-infauna. The term 'meio-epifauna' was introduced by Raes and Vanreusel (2005) to define the meiofauna living epifaunally on well-defined surfaces of diverse origin (biogenic debris, seagrasses, macro-algae, coral fragments, sponge skeletons, manganese nodules, pebbles, etc). According to their definition, suitable substrata for meio-epifauna (1) should be discrete and well-defined structures of at least about $5 \mathrm{~mm}$ in diameter and (2) should not be completely covered with sediment, implying that at least part of the surface area remains in contact with the water column. In the present study, suitable surfaces were found on large biogenic substrata, namely dead fragments of the framework building cold-water coral Lophelia pertusa (Linnaeus, 1758) and skeletons of the glass sponge Aphrocallistes bocagei (Schultze, 1886).

Dead coral fragments are the result of a bioerosion process that starts with the death of L. pertusa colonies due to the persistent attack by fouling organisms, the formation of a microbial biofilm and endolithic fungal infestation, followed by colonisation of the coral skeleton by sessile invertebrates such as sponges and octocorals (Freiwald and Wilson, 1998). Locally intense sponge excavation results in skeletal loss, and the in situ collapsing of the dead L. pertusa framework. On the other hand, the encrusting sponges speed up the closure of gaps in the open coral framework and promote sedimenttrapping, resulting in the strengthening of the framework architecture. This facies type is called sediment-clogged coral framework (Freiwald et al., 2002). In a final stage of the degradation process, intensified bioerosion results in accumulation of centimetre-sized coral rubble. Because of the dynamic origin of the habitat between living coral thickets and coral rubble, it is referred to as a 'coral degradation zone'.

Because of the sheltering function and higher habitat complexity of three-dimensionally branched coral skeletons, the diversity of megafauna living in the zones with living or dead coral framework is higher than that in the coral rubble zone (Mortensen et al., 1995). According to Mortensen et al. (1995) and Jensen and Frederiksen (1992), the dead coral framework harbors the most diverse macroand megafauna. Healthy, living L. pertusa responds to the settlement of sessile organisms by (1) an increase in mucus production and (2) selective sclerenchyme precipitation (Freiwald and Wilson, 1998). These protective properties have proven to be rather successful antifouling measures against macrofauna (Mortensen, 2000). For the same reasons, living coral is assumed not to be a suitable substratum for meiofauna.

Cold-water corals have been known to science since the 18th century (Pontoppidan, 1755). Nevertheless, the associated fauna has by no means been studied as intensively as it has for tropical corals. Moreover, most studies dealing with epifauna on either living or dead $L$. pertusa focused on the macro- and megafauna (Dons, 1944; Le Danois, 1948; Burdon-Jones and Tambs-Lyche, 1960; Jensen and Frederiksen, 1992; Mortensen et al., 1995; Fosså and Mortensen, 1998; Rogers, 1999).

The present paper provides a first overview of the nematode communities inhabiting cold-water coral degradation zones. Additionally, we aim to determine whether the trends observed by Raes and Vanreusel (2005) across the entire meiofaunal community on a higher taxon level can be specifically extended to a lower taxonomic level, i.e. within the nematode community. As in the case of deep-sea sediments that are not associated with large biogenic structures, nematodes are the dominant metazoan meiofaunal taxon in this deep-sea habitat.

The main topic of interest is the influence of habitat type on nematode community structure. For nematodes, the conditions within the sediment are different from those on a complex elevated structure on the sea floor. Next to this distinction between large biogenic substrata and the underlying sediment as a habitat, small differences in microhabitat structure could also influence the nematode community composition. Skeletons of dead L. pertusa in the Porcupine Seabight area are highly branched, dendroid structures with slender but solid branches and well-developed, cup-shaped corallites. The surface of the branches is smooth, although calcified tubes of the polychaete Eunice norvegica (Linnaeus, 1767) may be attached to the skeleton, and the coral surface is sometimes covered with a thin layer of bryozoan colonies. In contrast, skeletons of the glass sponge $A$. bocagei form a dense, complex, three-dimensional latticework of fine silica spicules. The underlying sediment in the area consists of Foraminifera-rich silty sand or soupy, foraminiferal sand. In the vicinity of coral banks the sediment becomes littered with coral fragments and other biogenic debris. 


\section{Materials and methods}

\subsection{Sampling sites and procedure}

Material was obtained by means of a round NIOZ (Netherlands Institute for Sea Research) box corer $(\varnothing 32 \mathrm{~cm})$. Two box cores were taken during the 9-19 June 2000 sampling campaign on the R.V. Belgica at $51^{\circ} 24^{\prime} 48.2^{\prime \prime} \mathrm{N} 11^{\circ} 45^{\prime} 55.4^{\prime \prime} \mathrm{W}$ and $51^{\circ} 24^{\prime} 49.4^{\prime \prime} \mathrm{N} 11^{\circ} 45^{\prime} 55.9^{\prime \prime} \mathrm{W}$. A third box core was taken at the same location during the 2-11 May 2001 sampling campaign on the same vessel, at $51^{\circ} 25^{\prime} 7.7^{\prime \prime} \mathrm{N} 11^{\circ} 46^{\prime} 9.3^{\prime \prime} \mathrm{W}$. All material originates from the top and slope of a single seabed mound at depths between 972 and $1005 \mathrm{~m}$, located in the Belgica mound province of the Porcupine Seabight (Fig. 1). The Porcupine Seabight is a large embayment of the European continental slope, located in the North-East Atlantic Ocean, southwest of Ireland.
In this area numerous seabed mounds occur, grouped in three so called 'mound provinces': the Hovland mound province, the Magellan mound province and the Belgica mound province (Fig. 1). The Belgica mound province is the most southern of the seabed mound provinces. The mounds in this province are known to be associated with deep-water coral banks, constructed mainly by the framework builder $L$. pertusa and associated fauna such as the glass sponge $A$. bocagei.

The presence of transversal sand dunes in the Belgica mound region indicates very high current velocities, up to $100 \mathrm{~cm} / \mathrm{s}$ (De Mol, 2002). Although these very high velocities are probably exceptional, normal current speeds are still considered high: about $10-25 \mathrm{~cm} / \mathrm{s}$ (White, 2006) or even $40-50 \mathrm{~cm} / \mathrm{s}$ (V. Huvenne, pers. comm.). High current speeds are attributed to the combination of strong, northward along-slope bottom currents, internal tides and

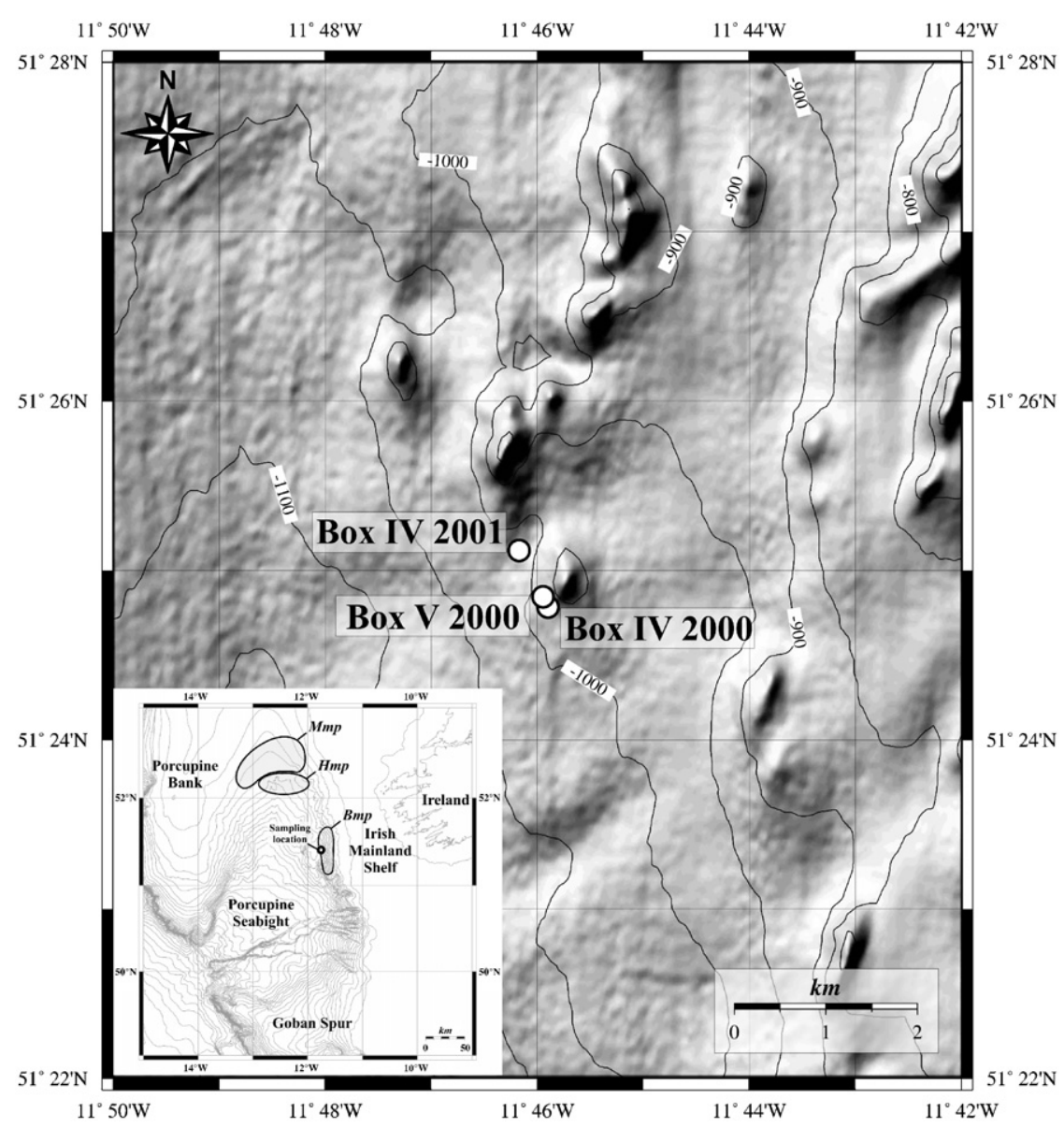

Fig. 1. Map of the Porcupine Seabight area and a detail showing the ridge of mounds in the Belgica mound province with indication of the exact box core locations (bathymetry after Beyer et al., 2003). (Mmp= Magellan mound province; Hmp = Hovland mound province; $B m p=$ Belgica mound province). 
waves, and the presence of mounds (Rice et al., 1991; Van Rooij et al., 2003; White, 2006).

The Porcupine Seabight area is also known to be subject to substantial phytodetrital deposition (Billett et al., 1983; Lampitt, 1985; Gooday et al., 1996). The detritus itself, as well as the bacteria and protozoa that rapidly colonize it, are the main food source for deep-sea meiofauna. Taking into account both timing of surface blooms in 2000 and 2001 as well as sinking rates (Billett et al., 1983), it was calculated that phytodetritus should have been present on the bottom on both sampling dates. It is, however, not clear whether this deposited material was available for the benthic fauna in the Belgica mound region, as strong bottom currents will certainly cause resuspension and relocation of the organic material. Down-slope and along-slope variability of phytodetrital deposition in this region makes generalizations even more difficult (D. Billett, pers. comm.). Our samples did not show any evidence of a detrital layer covering the sediment or the large biogenic substrata (pers. obs.).

In all cases, the surface of the sediment was partly or entirely covered with several fragments of dead corals ( $L$. pertusa) and dead sponge skeletons (A. bocagei). Only a very small amount of living coral was present. The large coral and sponge fragments were collected separately. After removal of the large biogenic substrata, three sediment cores $\left(10 \mathrm{~cm}^{2}\right)$ were pushed into the underlying sediment of each box core. All material was fixed with $4 \%$ buffered formalin. Each coral fragment, sponge fragment and sediment core is indicated here as a subsample.

\subsection{Material}

In total, 28 subsamples were examined: 18 subsamples were collected in the first box core from 2000 , six subsamples in the second box core from 2000 and another four subsamples in the box core from 2001. After thorough examination of its content, each subsample was classified into one of the following groups, each of them representing a microhabitat type: (1) dead coral fragments, (2) dead sponge skeletons (i.e. the two large biogenic substrata), (3) underlying sediment and (4) mixed substratum. The underlying sediment consisted of fine to medium sand (median $194.9 \mu \mathrm{m}$ ) with a small fine silt fraction and a high amount of planktonic foraminifera. It was observed that this was a poorly sorted sediment, also containing small fragments of both large biogenic substrata, as well as some small mollusc shells and echinoid spines. Subsamples belonging to the mixed substratum-group contained coral fragments as well as sponge skeletons and some sediment.

\subsection{Laboratory analyses}

Each Lophelia and Aphrocallistes fragment was rinsed thoroughly over sieves with mesh sizes of $1 \mathrm{~mm}$ and $32 \mu \mathrm{m}$ to separate macrofauna and meiofauna. Meiofauna was extracted from the underlying or remaining sediment by density gradient centrifugation, using Ludox (a colloidal silica polymer; specific gravity 1.18) as a flotation medium (Heip et al., 1985; Vincx, 1996). From each subsample, 200 nematodes (or a lower number when less than 200 nematodes were present in the examined subsample) were randomly picked out. They were subsequently mounted onto slides using the formalin-ethanol-glycerol technique described by Seinhorst (1959) and Vincx (1996), and identified to the genus level. Volumes of coral fragments and sponge skeletons were calculated by means of immersion.

The trophic composition of the nematode community was analyzed according to the classification of Wieser (1953) for reasons of comparability with other studies, although its practical application is no doubt questionable, and new feeding type classifications have been proposed (Moens and Vincx, 1997; Moens et al., 2004). Representatives of the families Benthimermithidae (Petter, 1980) and Rhaptothyreidae (Hope and Murphy, 1969) were eliminated from the trophic analysis because they are parasitic in their larval stages and the adults lack a buccal cavity.

\subsection{Statistical analyses}

The PRIMER5 software (Plymouth Marine Laboratory; Clarke and Gorley, 2001) was used to calculate Bray-Curtis similarities between all subsamples, ultimately resulting in a test statistic $R$ reflecting within-microhabitat as well as betweenmicrohabitat similarities. The obtained similarity matrix was applied to produce a non-metric multidimensional scaling two-dimensional plot (MDS). The stress value gives a measure for goodness-of-fit of the MDS ordination: a low stress value $(<0.2)$ indicates a good ordination with no real prospect for a misleading interpretation (Clarke, 1993). One-way analysis of similarities (ANOSIM) was 
performed to test for significant differences $(p<0.05)$ in the nematode community structure between the different microhabitats. Similarity of percentages (SIMPER) was carried out to investigate which genera were responsible for these differences. All absolute data were square root transformed prior to the analysis.

Several biodiversity indices were calculated: The Shannon-Wiener index $H^{\prime}\left(\log _{\mathrm{e}}\right)$ and Pielou's evenness $J$ (Pielou, 1975) are included mainly for reasons of comparability with other studies. Hill's diversity numbers (Hill, 1973) gradually change from indices of species richness to indices of dominance with increasing number: $N_{0}$ is identical to the number of species, $N_{1}=\exp \left(H^{\prime}\right)$ and $N_{\infty}$ reflects evenness. The expected number of genera for a theoretical sample of 100 individuals EG (100) was calculated in analogy with the expected number of species (Hurlbert, 1971). EG ()-values were also used to construct rarefaction curves.

Indicator genus analysis was performed using the PC-ORD4 software, by analogy with the indicator species analysis of Dufrêne and Legendre (1997). For this type of analysis absolute data were used without transformation. The mixed substratum subsamples were omitted from the analysis, and only the dominant genera $(>0.5 \%)$ were considered. Calculated indicator values were tested for statistical significance using a Monte Carlo test.

Parametric (one-way ANOVA) and non-parametric (Kruskal-Wallis ANOVA by ranks) analysis of variance was performed using the STATISTICA6 software. Cochran's C, Hartley's $F$ and Bartlett's Chi-square tests were used to verify the homogeneity of variances prior to the analysis.

\section{Results}

\subsection{Nematode community composition and habitat preferences}

In total, 5036 nematodes belonging to 136 different genera and 38 different families were included in the analysis. Of these 136 genera, 10 are considered new to science. Only 69 genera out of 136 were present in both the coral fragments, sponge skeletons and underlying sediment microhabitat. Table 1 lists the relative abundances of the 20 most abundant nematode genera for the coral, sponge, mixed and sediment microhabitats, calculated as the average of the relative abundance per subsample. All microhabitats, except for the coral fragment microhabitat, were dominated by Desmoscolex. Sabatieria was the second most abundant genus in the underlying sediment and Pselionema the second most abundant genus on sponge skeletons. The genus Epsilonema was dominant on dead coral fragments, but was not found among the 20 most abundant genera either on sponge skeletons or within the underlying sediment. Desmoscolex was the second most abundant genus on coral fragments.

Representatives of the closely related families Epsilonematidae and Draconematidae, which are characterized by an aberrant body shape, were found in all microhabitats and were especially abundant on the coral fragments. Three genera of Epsilonematidae (Epsilonema, Triepsilonema and Glochinema) and two genera of Draconematidae (Tenuidraconema and Cygnonema) were found amongst the 20 most abundant genera on coral fragments. Epsilonematids were much more abundant on coral fragments $(16.8 \%)$ and sponge skeletons $(6.1 \%)$ than in the underlying sediment $(2.7 \%)$. Draconematidae were also more abundant on coral fragments $(4.7 \%)$ and sponge skeletons $(1.4 \%)$ than in the underlying sediment $(0.5 \%)$. Only the epsilonematid Glochinema was found abundantly on both coral fragments, sponge skeletons and within the underlying sediment.

Although a certain degree of overlap between the different microhabitats in terms of associated nematofauna composition was obvious from the MDS graph (stress 0.15) given in Fig. 2, there was a clear trend in three directions, distinguishing between the three most distinct microhabitats: coral fragments, sponge skeletons and the underlying sediment (see arrows in Fig. 2). The mixed substratum subsamples took up a central position between these three microhabitats in the MDS graph. This distinction between microhabitats in terms of community structure was confirmed by a one-way analysis of similarities (ANOSIM): overall differences between all four microhabitats were very highly significant $(p=0.001)$. Pairwise tests revealed the absence of significant differences only between (1) the mixed substratum and sponge skeletons and between (2) the mixed substratum and the underlying sediment (Table 2). $R$ values were generally low, which was due to the observed overlap between the microhabitats (see MDS). Nevertheless, the number of actual permutations (between 210 and 999) was high enough to trust the significance levels. 
Table 1

Relative abundances of the 20 most abundant nematode genera and overall average densities (with standard deviations) of the nematofauna associated with cold-water coral degradation zones for each distinguished microhabitat. Representatives of the epifaunal families Epsilonematidae and Draconematidae are underlined

\begin{tabular}{|c|c|c|c|c|c|c|c|}
\hline \multicolumn{2}{|c|}{ Coral fragments (10) } & \multicolumn{2}{|c|}{ Sponge skeletons (8) } & \multicolumn{2}{|l|}{ Mixed substratum (4) } & \multicolumn{2}{|c|}{ Underlying sediment (6) } \\
\hline Genus & $(\%)$ & Genus & $(\%)$ & Genus & $(\%)$ & Genus & $(\%)$ \\
\hline Epsilonema & 8.51 & Desmoscolex & 7.85 & Desmoscolex & 9.66 & Desmoscolex & 9.01 \\
\hline$\overline{\text { Desmoscole } x}$ & 7.71 & Pselionema & 7.56 & Pselionema & 6.06 & Sabatieria & 8.27 \\
\hline Halalaimus & 6.84 & Halalaimus & 6.59 & Ceramonema & 4.96 & Acantholaimus & 6.78 \\
\hline Acantholaimus & 6.70 & Actinonema & 6.15 & Acantholaimus & 4.88 & Desmodora & 5.68 \\
\hline Anticoma & 4.94 & Ceramonema & 5.19 & Halalaimus & 4.62 & Halalaimus & 4.10 \\
\hline Theristus & 4.40 & Tricoma & 4.84 & Anticoma & 3.64 & Microlaimus & 3.09 \\
\hline Triepsilonema & 3.69 & Calomicrolaimus & 4.75 & Araeolaimoidea sp.1 & 3.52 & Tricoma & 3.04 \\
\hline$\overline{\text { Tricoma }}$ & 3.48 & Acantholaimus & 4.61 & Epsilonema & 3.23 & Syringolaimus & 3.03 \\
\hline Prochromadorella & 2.97 & Anticoma & 4.17 & Theristus & 3.23 & Bathynox & 2.92 \\
\hline Actinonema & 2.77 & Glochinema & 3.43 & Sabatieria & 2.81 & Ceramonema & 2.85 \\
\hline Tenuidraconema & 2.63 & $\overline{\text { Desmodora }}$ & 2.67 & Tricoma & 2.40 & Molgolaimus & 2.17 \\
\hline Cygnonema & 2.50 & Paracantonchus & 2.50 & Desmodora & 2.37 & Calomicrolaimus & 2.15 \\
\hline Calomicrolaimus & 2.34 & Sabatieria & 2.37 & Actinonema & 2.11 & Paracantonchus & 2.01 \\
\hline Glochinema & 2.17 & Monhystera & 2.30 & Triepsilonema & 2.09 & Aegialoalaimus & 1.94 \\
\hline$\overline{\text { Paracantonchus }}$ & 2.13 & Microlaimus & 1.83 & $\overline{\text { Paracantonchus }}$ & 2.08 & Halichoanolaimus & 1.82 \\
\hline Monhystera & 2.13 & Dichromadora & 1.62 & Monhystera & 2.03 & Monhystera & 1.80 \\
\hline Innocuonema & 2.12 & Prochromadorella & 1.57 & Prochromadorella & 1.99 & Glochinema & 1.64 \\
\hline Dichromadora & 2.08 & $\begin{array}{l}\text { Araeolaimoidea } \\
\text { sp.1 }\end{array}$ & 1.42 & Procamacolaimus & 1.90 & $\overline{\text { Araeolaimoidea sp.1 }}$ & 1.58 \\
\hline Chromadorina & 1.67 & Theristus & 1.29 & Viscosia & 1.46 & Anticoma & 1.54 \\
\hline Ceramonema & 1.64 & Metadasynemella & 1.17 & Microlaimus & 1.37 & Metadesmolaimus & 1.36 \\
\hline Average density & $\begin{array}{l}8915 \pm 2891 \\
\text { ind } / 1^{*}\end{array}$ & & $\begin{array}{l}49952 \pm 40660 \\
\text { ind } / 1\end{array}$ & & $\begin{array}{l}23039 \pm 19711 \\
\text { ind } / 1\end{array}$ & & $\begin{array}{l}301 \pm 102 \\
\text { ind } / 10 \mathrm{~cm}^{2}\end{array}$ \\
\hline
\end{tabular}

*For one substratum the volume could not be measured; average densities based only on the subsamples with known volume.

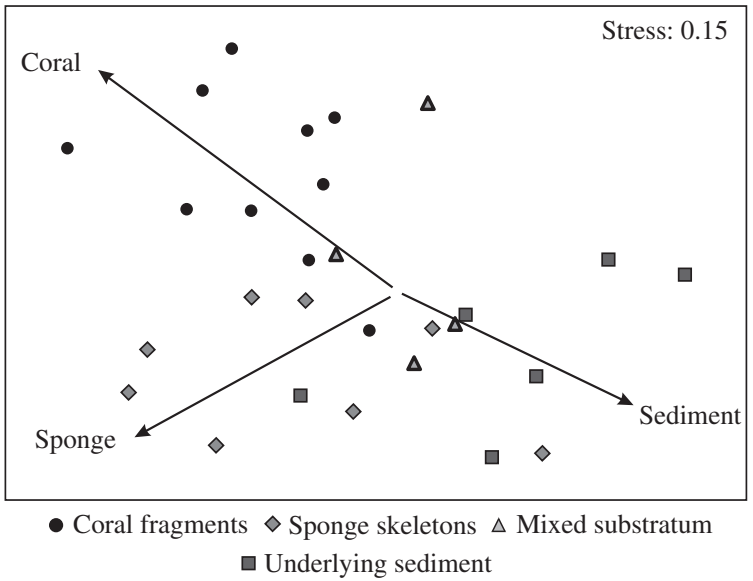

Fig. 2. Multidimensional scaling (MDS) two-dimensional plot of all subsamples. The trend in three directions, reflecting different communities in the three distinct microhabitats as mentioned in chapter 3.1 , is visualized here with three arrows radiating from the center.

Attention will be focused now on the coral fragments, the sponge skeletons and the underlying sediment. The average dissimilarity in community composition between sponge skeletons and the underlying sediment was $47.7 \%$ and mainly attributed to the higher abundance of Sabatieria in the underlying sediment (explains $3.4 \%$ of the dissimilarity) and Pselionema on the sponge skeletons (explains $3.1 \%$ of the dissimilarity), as indicated by SIMPER. The average dissimilarity between coral fragments and sponge skeletons was $46.6 \%$, explained mainly by Epsilonema (4.4\%, more abundant on coral fragments) and Pselionema (3.6\%, more abundant on sponge skeletons). The average dissimilarity between the underlying sediment and the coral framework, in terms of community composition, was the highest $(51.9 \%)$. This dissimilarity was explained mainly by Epsilonema (3.9\%, more abundant on coral fragments) and Sabatieria (3.2\%, more abundant in the interstices of the sediment).

All significant microhabitat preferences, as indicated by an indicator genus analysis, are summarized in Table 3. The analysis confirmed the above proposed habitat preferences: Sabatieria within the underlying sediment $(p=0.006)$, Pselionema on sponge skeletons $(p=0.006)$ and Epsilonema on dead coral fragments $(p=0.001)$. This analysis also indicated the preference of several representatives of 
Table 2

Results of ANOSIM pairwise test: values of the $R$ statistic and corresponding $p$-levels are indicated

\begin{tabular}{lllll}
\hline & Coral fragments & Sponge skeletons & Mixed substratum & Underlying sediment \\
\hline Coral fragments & & $* * *$ & $*$ & $* * *$ \\
Sponge skeletons & 0.44 & & $-* *$ & $*$ \\
Mixed substrate & 0.357 & 0.026 & 0.075 & $* *$ \\
Underlying sediment & 0.715 & 0.314 & \\
\hline
\end{tabular}

$* 0.01<p \leqslant 0.05$.

$* * \ldots p>0.05$.

$* * * p \leqslant 0.001$.

Table 3

Microhabitat preferences, as indicated by an indicator genus analysis. Only the statistically significant preferences are shown. Significance level is indicated. IV = Indicator Value

\begin{tabular}{|c|c|c|c|}
\hline Genus & $\begin{array}{l}\text { Preferred } \\
\text { microhabitat }\end{array}$ & IV & $\begin{array}{l}\text { Significance } \\
\text { level }\end{array}$ \\
\hline Actinonema & Sponge skeletons & 59 & $0.004^{* *}$ \\
\hline Aegialoalaimus & $\begin{array}{l}\text { Underlying } \\
\text { sediment }\end{array}$ & 57 & $0.024^{*}$ \\
\hline Akanthepsilonema & Coral fragments & 66 & $0.003^{* *}$ \\
\hline Bathyepsilonema & Sponge skeletons & 60 & $0.020^{*}$ \\
\hline Ceramonema & Sponge skeletons & 58 & $0.014^{*}$ \\
\hline Cygnonema & Coral fragments & 74 & $0.002^{* *}$ \\
\hline Epsilonema & Coral fragments & 89 & $0.001^{* * *}$ \\
\hline Halichoanolaimus & $\begin{array}{l}\text { Underlying } \\
\text { sediment }\end{array}$ & 64 & $0.004^{* *}$ \\
\hline Innocuonema & Coral fragments & 79 & $0.002^{* *}$ \\
\hline Molgolaimus & $\begin{array}{l}\text { Underlying } \\
\text { sediment }\end{array}$ & 61 & $0.011^{*}$ \\
\hline Prochromadorella & Coral fragments & 56 & $0.005^{* *}$ \\
\hline Pselionema & Sponge skeletons & 66 & $0.006^{* *}$ \\
\hline Sabatieria & $\begin{array}{l}\text { Underlying } \\
\text { sediment }\end{array}$ & 71 & $0.006^{* *}$ \\
\hline Syringolaimus & $\begin{array}{l}\text { Underlying } \\
\text { sediment }\end{array}$ & 76 & $0.002^{* *}$ \\
\hline Tenuidraconema & Coral fragments & 67 & $0.001^{* * *}$ \\
\hline Theristus & Coral fragments & 63 & $0.004^{* *}$ \\
\hline
\end{tabular}

$*_{0.01<p \leqslant 0.05}$.

$* * 0.001<p \leqslant 0.01$

$* * * p \leqslant 0.001$.

the closely related families Epsilonematidae and Draconematidae for the coral substratum: Akanthepsilonema $(p=0.003)$, Epsilonema (both Epsilonematidae), Cygnonema ( $p=0.002)$ and Tenuidraconema $(p=0.001)$ (both Draconematidae). Bathyepsilonema was the exception here: this epsilonematid genus preferred sponge skeletons $(p=0.02)$.

All microhabitats were dominated either by selective deposit feeders (Wieser group 1a) or by epistratum feeders (Wieser group 2a). Predators/ omnivores (Wieser group 2b) always constituted the least abundant group (Fig. 3). There were, however, small differences between the microhabitats: selective deposit feeders were the dominant trophic group in all microhabitats except for the coral fragments, which were dominated by epistratum feeders. This observed preference of epistratum feeders for the coral fragment microhabitat was statistically highly significant (ANOVA; df $=1$; $p=0.002)$ and attributed mainly to Epsilonema (IV $=65 ; p=0.001)$, as pointed out by an indicator genus analysis. The relative importance of both non-selective deposit feeders (Wieser group 1b) and predators/omnivores was clearly higher in the underlying sediment compared to both large biogenic substrata, with the mixed substratum taking up an intermediate position. The prevalence of predators/omnivores in the underlying sediment, in contrast to other microhabitats, was proven to be statistically very highly significant (ANOVA; $\mathrm{df}=1 ; p<0.001)$ and was attributed mainly to Syringolaimus (IV $=67 ; p=0.001)$.

\subsection{Densities}

Average nematode densities and standard deviations for each microhabitat are given in Table 1. Nematode densities are expressed as ind/ 1 on the substrata and as ind $/ 10 \mathrm{~cm}^{2}$ in the sediment for reasons of comparison with other studies. Densities tended to differ to a large extent between subsamples of the same microhabitat type as standard deviations were high. Nevertheless, the sponge skeletons were characterized by significantly higher densities of nematodes than the coral fragments (Kruskal-Wallis ANOVA; df $=1 ; p<0.001$ ).

\subsection{Biodiversity}

For all microhabitats a whole spectrum of biodiversity indices, ranging from indices of genus 


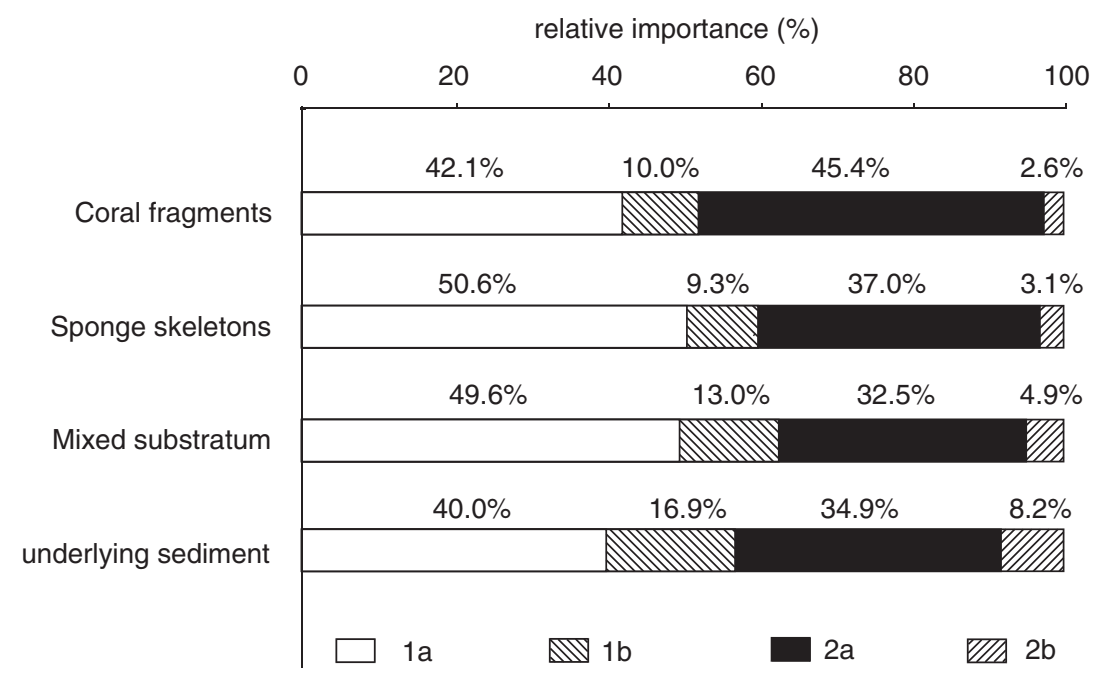

Fig. 3. Composition of Wieser (1953) feeding types for each microhabitat: selective deposit feeders (1a), non-selective deposit feeders (1b), epistratum feeders (2a) and predators/omnivores (2b).

Table 4

Biodiversity indices: Hill's diversity numbers $N_{0}, N_{1}$ and $N_{\infty}$, the expected number of genera for 100 individuals EG (100), the ShannonWiener diversity index $H^{\prime}$ and Pielou's evenness $J$. Under (a) the average value over all subsamples, with its standard deviation, is given, under (b) the value for the pooled data of all subsamples for the respective microhabitat. The $p$-level indicates the overall statistical significance level for the observed differences between microhabitats

\begin{tabular}{llllllll}
\hline & & $N_{0}$ & EG $(100)$ & $N_{1}$ & $H^{\prime}$ & $J$ \\
\hline Coral fragments & (a) & $40.60 \pm 8.78$ & $33.47 \pm 5.07$ & $26.48 \pm 5.85$ & $3.25 \pm 0.23$ & $0.88 \pm 0.03$ & $8.03 \pm 2.10$ \\
& (b) & 93 & 38.41 & 40.13 & 3.69 & 0.81 \\
Sponge skeletons & (a) & $42.38 \pm 10.81$ & $33.70 \pm 5.04$ & $25.63 \pm 6.38$ & $3.22 \pm 0.25$ & $0.86 \pm 0.04$ & $7.51 \pm 1.96$ \\
& (b) & 93 & 38.00 & 39.44 & 3.67 & 0.81 \\
Mixed substratum & (a) & $53.25 \pm 4.57$ & $40.34 \pm 5.52$ & $34.09 \pm 5.53$ & $3.52 \pm 0.16$ & $0.89 \pm 0.03$ & $9.43 \pm 1.48$ \\
& (b) & 91 & 43.40 & 47.20 & 3.85 & 0.85 \\
Underlying sediment & (a) & $51.00 \pm 2.45$ & $40.26 \pm 2.48$ & $32.16 \pm 3.98$ & $3.46 \pm 0.13$ & $0.88 \pm 0.04$ & $8.36 \pm 2.95$ \\
& (b) & 106 & 43.29 & 47.26 & 3.86 & 0.83 & 10.94 \\
$p$-level & & $0.02^{*}$ & $0.03 *$ & $0.04^{*}$ & $0.05^{*}$ & 0.58 (NS) & 0.56 (NS) \\
\hline
\end{tabular}

(NS) not significant $(p>0.05)$.

* Significant $(0.01<p \leqslant 0.05)$.

richness $\left(N_{0}, \mathrm{E} G(100)\right)$ to indices of evenness $\left(J, N_{\infty}\right)$, is given in Table 4. Dominance was generally low, and there were no significant differences between microhabitats in terms of evenness (ANOVA; $J$ and $N_{\infty}$ ). The sediment clearly harbored the highest number of genera $N_{0}$, whereas the other microhabitats had more or less the same number of genera. It should be noted that the coral fragments and sponge skeletons yielded nevertheless the highest number of individuals. It was found that on average, both substrata were characterized by a significantly lower number of genera compared to the underlying sediment and the mixed substratum (Kruskal-Wallis ANOVA; $\mathrm{df}=1 ; p=0.016)$. This was confirmed by a comparison of the EG (100) values (Kruskal-Wallis ANOVA; $\mathrm{df}=1 ; p=0.02)$. Moreover, Hill's $N_{1}$ (ANOVA; $\mathrm{df}=1 ; p=0.004$ ) and the Shannon-Wiener index $H^{\prime}$ (ANOVA; df $=1 ; p=0.005$ ) were also significantly higher for the sediment and mixed substratum microhabitats than for both separate substrata. 
The rarefaction curves for the total community associated with each microhabitat and for the entire community combined over all microhabitat types (pooled data) (Fig. 4) show that the expected number of genera for coral fragments and sponge skeletons falls below that of the sediment and the mixed substratum. The presence of these substrata even lowers the value for the added-up community in comparison with the sediment. This combined community is not to be interpreted as a representation of the natural situation as it is not possible to calculate the relative importance of the three microhabitats in the cold-water coral degradation zone.

\section{Discussion}

The present paper is part of the first comprehensive study dealing with the community structure, habitat preferences and biodiversity of the metazoan meiofaunal community associated with coldwater coral degradation zones (Raes and Vanreusel, 2005). The main conclusions of this study, which dealt with meiofauna at higher (i.e. coarser) taxonomic levels, are briefly as follows. The meioinfaunal community composition in the sediment beneath the large biogenic substrata was similar to that of other slope sediments. However, the meioepifaunal community associated with the large biogenic substrata was significantly different from the meio-infauna: it was characterized by a lower dominance of nematodes and higher abundances of several other taxa. This indicates a positive influence of large biogenic substrata on the number of taxa present in the whole ecosystem. In particular, coral fragments housed a characteristic community that was significantly different from that found in the sediment. Nevertheless, the meio-epifauna was composed of a typical sediment-dwelling background community, supplemented with taxa adapted to an epifaunal life strategy. This was attributed to the presence of sediment infill within the framework of both substrata and the close contact with the underlying sediment. Densities in the underlying sediment were low. In contrast, both large biogenic substrata were thought to be lowdisturbance habitats, rich in food and hence densely populated. Because of these properties of the two substratum types, the high microhabitat diversity and the low dominance of nematodes, cold-water coral degradation zones were assumed to be biologically diverse. Of all microhabitat types, coral fragments supported the most diverse communities, whereas the underlying sediment was the least diverse. Whether the same conclusions can be drawn for the nematode community at a generic level will be discussed next.

\subsection{Nematode community composition and habitat preferences}

Dead coral fragments and sponge skeletons lie relatively unprotected on the sea floor. The fauna associated with these substrata could therefore be

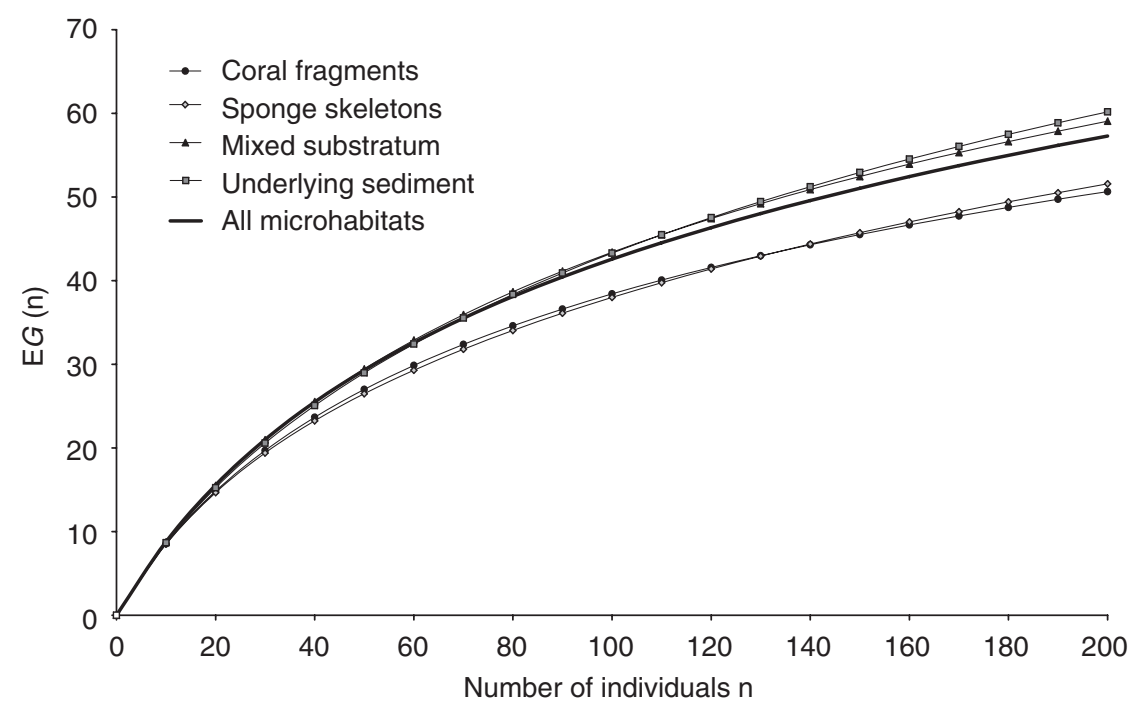

Fig. 4. Rarefaction curves for the pooled data for each microhabitat and for the combined community over all microhabitats. 
strongly influenced by the vigorous bottom currents that prevail in the area (White, 2006). The danger of physical erosion and removal by these hydrodynamic forces prevents most nematode taxa from living here. However, taxa that are able to withstand the currents' eroding effect will have an advantage in these exposed habitats. Coral fragments were dominated by Epsilonema, a nematode belonging to the family Epsilonematidae. SIMPER showed that Epsilonema was the main explanatory taxon for the dissimilarity between coral fragments on the one hand and sponge skeletons and sediment on the other hand. This is remarkable given that Epsilonematidae were, until recently (Neira et al., 2001, 2005; Gad, 2002, 2004; Raes et al., 2003, 2006), unknown from deep-sea habitats (Decraemer et al., 2001). Moreover, both Epsilonematidae and the closely related Draconematidae were much more abundant on coral fragments than in either of the other microhabitats, and an indicator genus analysis revealed significant preferences of two epsilonematid and two draconematid genera for the coral fragment microhabitat. Because of their peculiar locomotory pattern and morphology, Epsilonematidae and Draconematidae are well-adapted to living with physical disturbance. First of all, representatives of both families are known to move forward over a substratum just like looper-caterpillars, alternately attaching and releasing the anterior and posterior end of the body (Stauffer, 1924; Lorenzen, 1973). To perform this kind of locomotion, they possess typical locomotory structures known as cephalic and posterior adhesion tubes (Draconematidae) or ambulatory setae (Epsilonematidae), which they can use together with the caudal glands to attach themselves firmly to a substratum and hence better withstand removal by current activity. Secondly, most Epsilonematidae (e.g. Epsilonema) are stout, heavily cuticularized nematodes, which makes them more stable and less vulnerable to physical damage. The idea that small, short and stout nematodes, which are characterized by higher growth rates and a reduced age at first breeding and which are more able to withstand different types of disturbance, act as opportunists in shallow and ocean-margin areas, has been proposed by several authors (Soetaert et al., 2002; Vanaverbeke et al., 2004). Desmoscolex is also a stout nematode with a cuticle strengthened by bands of secretion and foreign material, called desmen. According to Stauffer (1924), Desmoscolex also moves forward like a caterpillar, using specialized setae associated with glands, which are located subdorsally. In this way Desmoscolex is able to firmly attach itself to a substratum, which might partly explain its high abundance on both large biogenic substrata. On the other hand, Desmoscolex was also the dominant genus in the underlying sediment. This nematode is considered a typical sediment-dwelling genus for these depths (Soetaert and Heip, 1995; Vanaverbeke et al., 1997), and its importance on both large biogenic substrata could well be the result of considerable sediment infill.

The nematofauna inhabiting the underlying sediment is relatively protected from current activity by the substrata that cover it, which means that its composition is not fundamentally structured by physical disturbance. As a result, the opportunistic Epsilonematidae and Draconematidae are much less abundant here in comparison with the substrata, and most nematodes in the sediment-dwelling community belong to the slender morphotype typical for an interstitial microhabitat (Giere, 1993). This is thought to be the reason why the sediment communities and coral communities are so different from each other. Only Vanaverbeke et al. (1997) have described the nematode genus composition in sediment not associated with large biogenic structures at a nearby location (Goban Spur) and at a comparable depth. Station B in their study was located at a depth of $1034 \mathrm{~m}$ and is therefore our main source for comparison. The nematode community at this station appears to be dominated by Acantholaimus and Sabatieria. However, the genera Desmoscolex and Pareudesmoscolex were counted separately in this study, although Pareudesmoscolex is considered a subgenus of Desmoscolex (Decraemer, 1985) and was accordingly identified in our study. Thus, when the relative abundances of these two genera at station B of Vanaverbeke et al. (1997) are added up, a co-dominance of Desmoscolex (9.8\%), Acantholaimus $(9.8 \%)$ and Sabatieria $(9.3 \%)$ arises. This corresponds relatively well with what was found in the underlying sediment of our study. Sabatieria and Acantholaimus are considered typical slope genera for the North Atlantic and Mediterranean (Soetaert and Heip, 1995). According to Vanaverbeke et al. (1997), Acantholaimus and Desmoscolex are typical deep-sea genera that are also frequently found on the lower slope (i.e. station $\mathrm{B}$ and deeper stations), whereas Sabatieria is more abundant at shallower stations (see also Soetaert and Heip, 1995). Except for Desmodora, the eight most abundant genera in the underlying sediment of 
our study were also found among the 20 most abundant genera in station B of Vanaverbeke et al. (1997). It can be concluded that, despite the presence of small fragments of both large biogenic substrata, mollusc shells and echinoid spines within the underlying sediment in cold-water coral degradation zones, the nematode communities are still dominated by typical soft sediment slope taxa. In contrast to normal slope sediments, which are not supplemented with these biogenic structures, epsilonematids and draconematids were still relatively well-represented in the underlying sediment of our study. Nevertheless, the only epsilonematid among the 20 most abundant genera here was Glochinema (subfamily Glochinematinae). This is a long and slender nematode, supported by long and fine ambulatory setae, and is therefore less stable and more vulnerable to current activity than most other, shorter and thicker Epsilonematidae. So this might be more of a sediment dweller, taking advantage of the presence of smaller substrata within the underlying sediment. On the other hand, several representatives of the subfamily Glochinematinae have been found in soft sediments (Gad, 2004). Sabatieria plays an important role in the underlying sediment. The dissimilarity between the sediment and both other microhabitats was attributed mainly to this genus, and indicator genus analysis revealed significant preferences of Sabatieria for the sediment microhabitat. As argued above, Sabatieria is a typical slope genus. According to Soetaert and Heip (1995), Sabatieria also has a preference for suboxic or anoxic environments. This is very interesting, given that the depth distribution of cold-water coral reefs in the Porcupine Seabight coincides with the OMZ (Oxygen Minimum Zone) layer in this area (Freiwald, 2003).

Although sponge skeletons are also large biogenic structures that stick out from the sediment, they house a community significantly different from the one associated with coral fragments (Table 2; Fig. 2). Moreover, this microhabitat does not favor the epifaunal taxa as strongly as the coral fragments. As in the underlying sediment, the only abundant epsilonematid here is Glochinema. We propose a structural explanation for this discrepancy. Because of its complex, three-dimensional latticework of fine silica spicules, a glass sponge skeleton is probably able to trap more sediment than a dead coral framework. It was observed that the dead sponge skeletons were coloured greyishbrown and that a considerable amount of sediment was accumulated in the central spongocoel. In contrast, only a small amount of sediment was accumulated in the felty layer of bryozoan colonies, which covered parts of the surface of the coral fragments (M. Raes, pers. obs.). As a result, the sponge microhabitat is more suitable for slender, sediment-dwelling taxa than the coral habitat. Nematodes could also be slightly more protected from physical erosion in this microhabitat, which means that opportunistic epifaunal taxa will have fewer advantages here. On the other hand, the spicules might still serve as a suitable substratum for epifaunal nematodes, as indicated by the observed preference of Bathyepsilonema for sponge skeletons. The indicator genus analysis revealed only two other indicator genera for this microhabitat, Pselionema and Ceramonema. Both ceramonematids are heavily armored nematodes, which is again interpreted as an adaptation to physical disturbance by hydrodynamic forces. However, it must also be mentioned here that Ceramonematidae are not uncommon in slope soft sediments (Vanaverbeke et al., 1997).

Although the communities in different microhabitats were significantly dissimilar from each other, the MDS-biplot (Fig. 2), the low $R$-values (ANOSIM; Table 2) and the low average dissimilarity numbers (SIMPER) indicate a considerable degree of overlap. Accumulation of sediment between the sponge spicules or coral branches and the presence of small fragments of both biogenic substrata within the sediment are introduced here as explanations. Sediment infill is caused either by close contact between the biogenic substrata and the underlying sediment or by the deposition of suspended material. It is assumed that the nematofauna associated with large biogenic substrata in coldwater coral degradation zones is composed of a typical slope sediment-dwelling, interstitial background community, supplemented with taxa adapted to an epifaunal life strategy. The extent to which these epifaunal taxa contribute to the community depends on the substratum type. The central position of the mixed substratum subsamples on the MDS biplots also reflects the combined effect of the three microhabitat types on the nematode community structure.

The nematode communities on the continental slope are usually dominated by selective and nonselective deposit feeders (Soetaert and Heip, 1995). However, in station B of Vanaverbeke et al. (1997) there was a co-dominance of these two trophic 
groups and the epistratum feeders. Thus, the trophic composition of the nematode communities in the present study can be considered normal for this location and this depth. The statistically significant preference of epistratum feeders for coral fragments is attributed to the presence of a microbial biofilm that covers the surface of these structures (Freiwald and Wilson, 1998) and might act as an important food source here. This preference was attributed mainly to Epsilonema. Indeed, when epsilonematids or draconematids 'walk' over the dead coral fragments, their buccal cavity is ideally positioned for feeding on the biofilm. The prevalence of predators/omnivores in the underlying sediment could be related to the presence of a more stable community in this relatively undisturbed microhabitat.

\subsection{Densities}

As nematode densities on both substrata in our study are expressed as individuals per unit of volume (i.c. ind/l), comparison with other studies dealing with epifauna, e.g. on seagrasses or macroalgae, is impossible as densities are usually expressed as individuals per unit of surface area. Because of the irregularity and three-dimensional complexity of the substrata at hand, it was impossible to measure the exact surface area. Moreover, the accumulation of sedimented material on the substrata obscures the concept of total available surface area. The significantly higher densities of nematodes on sponge skeletons compared to the dead coral fragments can be explained by the higher degree of sediment infill in the former substratum. The presence of interstitial microniches is considered essential for nematode colonisation (Danovaro and Fraschetti, 2002), and sediment infill might therefore be essential to the building of a well-developed, and hence dense, nematode community. Moreover, Giere (1993) stated that most nematodes are morphologically more adapted to move between the sand grains than to crawl over a substratum.

According to Raes and Vanreusel (2005), the sediment-clogged coral framework and associated glass sponge skeletons could be densely populated by meiofauna as a result of low disturbance, low predation pressure and abundant food. However, the nematode data contradict low disturbance on these substrata. Moreover, the same authors observed significantly lower abundances of nematodes on these substrata.

In the underlying sediment, densities varied between 166 and $429 \mathrm{ind} / 10 \mathrm{~cm}^{2}$. This number is consistently lower than in the studies of Pfannkuche (1985) (Porcupine Seabight—960 m, 1429 ind $/ 10 \mathrm{~cm}^{2}$; $1492 \mathrm{~m}, 820 \mathrm{ind} / 10 \mathrm{~cm}^{2}$ ), Vanaverbeke et al. (1997) (Goban Spur $-670 \mathrm{~m}, \quad 580 \mathrm{ind} / 10 \mathrm{~cm}^{2} ; \quad 1034 \mathrm{~m}$, $587.5 \mathrm{ind} / 10 \mathrm{~cm}^{2} ; 1425 \mathrm{~m}, 482 \mathrm{ind} / 10 \mathrm{~cm}^{2}$ ) and Gooday (unpubl. in Vincx et al., 1994) (Porcupine Seabight $-1340 \mathrm{~m}, 1026-1211 \mathrm{ind} / 10 \mathrm{~cm}^{2}$ ). All of these studies were carried out at nearby locations, at comparable depths and, in the case of the study by Pfannkuche (1985), at a similar time in the year. Raes and Vanreusel (2005) proposed several potential explanations for the low meiofaunal densities in the underlying sediment: (1) effect of different sampling gear; (2) limited food supply due to phytodetritus-trapping by the coral framework which covers the sediment or (3) due to strong currents; (4) physical removal by strong currents; (5) presence of biogenic structures in the sediment or (6) high predation pressure. As argued above, the erosive effect of current activity (fourth explanation) is thought to be rather limited in the underlying sediment.

\subsection{Biodiversity}

Several indices $\left(N_{0}, \mathrm{E} G(100), N_{1}, H^{\prime}\right)$ indicated a significantly higher diversity in the underlying sediment compared to both large biogenic substrata, despite the expected higher habitat complexity of the branched coral fragments and the network of sponge spicules compared to the interstitial habitat, especially when the sediment infill between these structures is taken into account. As mentioned above, both substrata, especially the coral fragments, are rather hostile environments for most nematodes and the majority of nematodes are better adapted to an interstitial life strategy (Giere, 1993). The interstitial habitat of the underlying sediment is a more suitable one for nematodes than the substratum surface and is relatively undisturbed, enabling a more diverse community to establish itself in the former habitat. Consistent with this idea, Gage et al. (1995) found that macrofaunal species diversity was markedly depressed by high current energy in the deep sea. It appears that only a few, well-adapted nematodes can thrive on the substrata, whereas the other genera are dependent on the presence of sediment infill, especially for 
sponge skeletons. This is, however, not reflected in the indices of evenness. Thus it seems that although fewer genera are able to live in these more disturbed microhabitats, the community is not merely dominated by the best adapted ones. Our results also indicate that the presence of a higher number of epifaunal genera on these substrata is not able to compensate for the loss in genus richness due to the physical erosion by strong currents.

The presence of small biogenic structures in the underlying sediment considerably adds to its habitat complexity and heterogeneity and therefore its biodiversity. Hence, both interstitial and epifaunal taxa will be present here, and their combined presence increases genus richness. This is confirmed by the high $N_{0}$-value of the sediment. Furthermore, this value is much higher than for the Goban Spur stations I, B and II in Vanaverbeke et al. (1997) (106 vs. 45-72), although fewer individuals were identified. The same is true for $N_{1}$ and $\mathrm{E} G$ (100). The higher genus richness of the nematode community on the mixed substratum can easily be explained as this community recruits from both the sponge and coral communities, each with a different genus composition.

Both coral fragments and sponge skeletons provide a microhabitat for representatives of the Epsilonematidae and Draconematidae, which are rare or not yet recorded elsewhere along the continental margin and in the deep sea (Decraemer et al., 2001; Gad, 2004), and small degradation products of the two substrata positively influence the biodiversity in the underlying sediment. The importance of such 'habitat islands' for deep-sea fauna has been confirmed by Gage (1996), who states that they attract aggregations of species, including many specialist taxa that are very rare in the background community.

In conclusion, the nematode data largely confirm the hypotheses proposed by Raes and Vanreusel (2005) for taxa at a higher taxonomic level. However, these data contradict low disturbance on the large biogenic substrata. In addition, the nematode community in the underlying sediment is significantly more diverse than on the coral fragments, whereas the opposite is true for the meiofaunal community at a higher taxonomic level.

\section{Acknowledgements}

The authors wish to thank Dr. Véronique Vanquickelberghe and Guy De Smet for their sampling efforts and Wies Gyselinck, Annick Van Kenhove, Danny Peelaers, Bart Beuselinck and Daniëlle Schram for meiofauna extraction, granulometric analysis and for making lots of excellent Cobb slides. Special thanks go to Dr. Jan Vanaverbeke, three anonymous reviewers and Andy Gooday for critically reading the manuscript and for providing many constructive remarks. Prof. Dr. Jean-Pierre Henriet and the people from the Renard Centre of Marine Geology, as well as the crew of the R.V. Belgica, are acknowledged for a successful collaboration. The first author acknowledges a $\mathrm{Ph} . \mathrm{D}$. grant provided by the Fund for Scientific Research (FWO-Vlaanderen), Belgium. This research was conducted within the framework of the Atlantic Coral Ecosystem Study (ACES) (EC Fifth Framework Research Programme), the HERMES project (EC Sixth Framework Research Programme under the priority 'Sustainable Development, Global Change and Ecosystems') and the national FWO Research Project G.0199.03.

\section{References}

Beyer, A., Schenke, H.W., Klenke, M., Niederjasper, F., 2003. High resolution bathymetry of the eastern slope of the Porcupine Seabight. Marine Geology 198, 27-54.

Billett, D.S.M., Lampitt, R.S., Rice, A.L., 1983. Seasonal sedimentation of phytoplankton to the deep-sea benthos. Nature 302, 520-522.

Burdon-Jones, C., Tambs-Lyche, H., 1960. Observations on the fauna of the North Brattholmen stone-coral reef near Bergen. Årbok for Universitetet I Bergen (Matematisk-naturvitenskapelig serie) 4, 1-24.

Clarke, K.R., 1993. Non-parametric multivariate analyses of changes in community structure. Australian Journal of Ecology 18, 117-143.

Clarke, K.R., Gorley, R.N., 2001. PRIMER v5: User Manual/ Tutorial. PRIMER-E, Plymouth.

Danovaro, R., Fraschetti, S., 2002. Meiofaunal vertical zonation on hard-bottoms: comparison with soft-bottom meiofauna. Marine Ecology Progress Series 230, 159-169.

Decraemer, W., 1985. Revision and phylogenetic systematics of the Descmoscolecida (Nematoda). Hydrobiologia 120, 259-283.

Decraemer, W., Gourbault, N., Helléouet, M.-N., 2001. Cosmopolitanism among nematodes: examples from Epsilonematidae. Vie et Milieu 51, 11-19.

De Mol, B., 2002. Development of coral banks in Porcupine Seabight (SW Ireland): A multidisciplinary approach. Ph.D. Thesis, Ghent University, Ghent, Belgium, unpublished.

Dons, C., 1944. Norges korallrev. Det Kongelige Norske Videnskabers Selskabs Forhandlinger 16, 37-82.

Dufrêne, M., Legendre, P., 1997. Species assemblages and indicator species: the need for a flexible asymmetrical approach. Ecological Monographs 67, 356-366. 
Fosså, J.H., Mortensen, P.B., 1998. Artsmangfoldet på Lopheliakorallrev og metoder for overvåkning. Fisken og Havet 17, $1-95$.

Freiwald, A., 2003. Reef-forming Cold-Water Corals. In: Wefer, G., Billett, D., Hebbeln, D., Jørgensen, B.B., Schlüter, M., van Weering, T. (Eds.), Ocean Margin Systems. Springer, Berlin Heidelberg, pp. 365-385.

Freiwald, A., Wilson, J.B., 1998. Taphonomy of modern deep, cold-temperate water coral reefs. Historical Biology 13, $37-52$.

Freiwald, A., Hühnerbach, V., Lindberg, B., Wilson, J.B., Campbell, J., 2002. The Sula Reef Complex, Norwegian Shelf. Facies 47, 179-200.

Gad, G., 2002. The relation between habitus and habitat structure as evidenced by a new species of Glochinema (Nematoda, Epsilonematidae) from the plateau of the Great Meteor Seamount. Hydrobiologia 474, 171-182.

Gad, G., 2004. Diversity and assumed origin of the Epsilonematidae (Nematoda) of the plateau of the Great Meteor Seamount. Archive of Fishery and Marine Research 51, $30-42$.

Gage, J.D., 1996. Why are there so many species in deep-sea sediments? Journal of Experimental Marine Biology and Ecology 200, 257-286.

Gage, G.D., Lamont, P.A., Tyler, P.A., 1995. deep-sea macrobenthic community structure at contrasting sites off Portugal, preliminary results: 1 Introduction and diversity comparisons. Internationale Revue der Gesamten Hydrobiologie 80, 235-250.

Giere, O., 1993. Meiobenthology: the microscopic fauna in aquatic sediments. Springer, Berlin.

Gooday, A.J., Pfannkuche, O., Lambshead, P.J.D., 1996. An apparent lack of response by metazoan meiofauna to phytodetrital deposition in the bathyal North-Eastern Atlantic. Journal of the Marine Biological Association of the United Kingdom 76, 297-310.

Heip, C., Vincx, M., Vranken, G., 1985. The ecology of marine nematodes. Oceanography and Marine Biology Annual Review 23, 399-489.

Hill, M.O., 1973. Diversity and evenness: a unifying notation and its consequences. Ecology 54, 427-432.

Hurlbert, S.H., 1971. The non-concept of species diversity: a critique and alternative parameters. Ecology 52, 577-586.

Jensen, A., Frederiksen., R., 1992. The fauna associated with the bank-forming deepwater coral Lophelia pertusa (Scleractinaria) on the Faroe shelf. Sarsia 77, 53-69.

Lampitt, R.S., 1985. Evidence for the seasonal deposition of detritus to the deep-sea floor and its subsequent resuspension. Deep-Sea Research 32, 885-897.

Le Danois, E., 1948. Les profondeurs de la mer. Trente ans de recherche sur la faune sous-marine au large des côtes de France. Payot, Paris.

Lorenzen, S., 1973. Die familie Epsilonematidae (Nematodes). Mikrofauna des Meeresbodens 25, 1-86.

Moens, T., Vincx, M., 1997. Observations on the feeding ecology of estuarine nematodes. Journal of the Marine Biological Association of the United Kingdom 77, 211-227.

Moens, T., Yeates, G.W., De Ley, P., 2004. Use of carbon and energy sources by nematodes. Nematology Monographs \& Perspectives 2, 529-545.

Mortensen, P.B., 2000. Lophelia pertusa (Scleractinia) in Norwegian waters: distribution, growth, and associated fauna. Ph.D.
Thesis, Department of Fisheries and Marine Biology, University of Bergen, Norway, unpublished.

Mortensen, P.B., Hovland, M., Brattegard, T., Farestveit, R., 1995. Deep water bioherms of the scleractinian coral Lophelia pertusa (L.) at $64^{\circ} \mathrm{N}$ on the Norwegian shelf: structure and associated megafauna. Sarsia 80, 145-158.

Neira, C., Gad, G., Arroyo, N.L., Decraemer, W., 2001. Glochinema bathyperuvensis sp. n. (Nematoda, Epsilonematidae): A new species from Peruvian bathyal sediments, SE Pacific Ocean. Contributions to Zoology 70, 147-159.

Neira, C., Decraemer, W., Backeljau, T., 2005. A new species of Glochinema (Epsilonematidae: Nematoda) from the oxygen minimum zone off Baja California, NE Pacific and phylogenetic relationships at species level within the family. Cahiers de Biologie Marine 46, 105-126.

Pfannkuche, O., 1985. The deep-sea meiofauna of the Porcupine Seabight and abyssal plain (NE Atlantic): population structure, distribution, standing stocks. Oceanologica Acta 8, 343-353.

Pielou, E.C., 1975. Ecological diversity. Wiley, New York.

Pontoppidan, E., 1755. The Natural history of Norway. A Linde, London.

Raes, M., Vanreusel, A., 2005. The metazoan meiofauna associated with a cold-water coral degradation zone in the Porcupine Seabight (NE Atlantic). In: Freiwald, A., Roberts, J.M. (Eds.), Cold-water Corals and Ecosystems. Springer, Berlin Heidelberg, pp. 821-847.

Raes, M., Vanreusel, A., Decraemer, W., 2003. Epsilonematidae (Nematoda) from a cold-water coral environment in the Porcupine Seabight, with a discussion on the status of the genus Metaglochinema Gourbault \& Decraemer, 1986. Hydrobiologia 505, 49-72.

Raes, M., Decraemer, W., Vanreusel, A., 2006. Postembryonic Morphology in Epsilonematidae, with a Discussion on the Variability of Caudal Gland Outlets. Journal of Nematology 38, 97-118.

Rice, A.L., Billett, D.S.M., Thurston, M.H., Lampitt, R.S., 1991. The Institute of Oceanographic Sciences Biology Programme in the Porcupine Seabight: background and general introduction. Journal of the Marine Biological Association of the United Kingdom 71, 281-310.

Rogers, A.D., 1999. The biology of Lophelia pertusa (Linnaeus 1758) and other deep-water reef-forming corals and impacts from human activities. International Review of Hydrobiology 84, 315-406.

Seinhorst, J.W., 1959. A rapid method for the transfer of nematodes from fixative to anhydrous glycerine. Nematologica 4, 67-69.

Soetaert, K., Heip, C., 1995. Nematode assemblages of deep-sea and shelf break sites in the North Atlantic and Mediterranean Sea. Marine Ecology Progress Series 125, 171-183.

Soetaert, K., Muthumbi, A., Heip, C., 2002. Size and shape of ocean margin nematodes: morphological diversity and depthrelated patterns. Marine Ecology Progress Series 242, 179-193.

Stauffer, H., 1924. Die Lokomotion der Nematoden. Beiträge zur Kausalmorphologie der Fadenwürmer. Zoologischer Jahrbücher 49, 1-118.

Vanaverbeke, J., Soetaert, K., Heip, C., Vanreusel, A., 1997. The metazoan meiobenthos along the continental slope of the Goban Spur (NE Atlantic). Journal of Sea Research 38, 93-107. 
Vanaverbeke, J., Soetaert, K., Vincx, M., 2004. Changes in morphometric characteristics of nematode communities during a spring phytoplankton bloom deposition. Marine Ecology Progress Series 273, 139-146.

Van Rooij, D., De Mol, B., Huvenne, V., Ivanov, M., Henriet, J.P., 2003. Seismic evidence of current-controlled sedimentation in the Belgica mound province, upper Porcupine slope, southwest of Ireland. Marine Geology 195, 31-53.

Vincx, M., 1996. Meiofauna in marine and freshwater sediments. In: Hall, G.S. (Ed.), Methods for the examination of organismal diversity in soils and sediments. Cab International, pp. 187-195.
Vincx, M., Bett, B.J., Dinet, A., Ferrero, T., Gooday, A.J., Lambshead, P.J.D., Pfannkuche, O., Soltwedel, T., Vanreusel, A., 1994. Meiobenthos of the deep northeast Atlantic. Advances in Marine Biology 30, 2-88.

White, M., 2006. Benthic dynamics at the carbonate mound regions of the Porcupine Sea Bight continental margin. International Journal of Earth Sciences, doi:10.10007/ s00531-006-0099-1.

Wieser, W., 1953. Die Beziehung zwischen Mundhöhlengestalt, Ernährungsweise und Vorkommen bei freilebenden marinen Nematoden. Eine ökologisch-morphologische Studie. Arkiv för Zoologi 4, 439-483. 